\title{
Nobel Recognition for Ethology
}

\section{Professors R. A. Hinde and W.H. Thorpe of Cam- bridge University Sub- department of Animal. Behaviour assess the sig- nificance of the award last week of a Nobel Prize to three animal behaviour- ists.}

THE award of the Nobel Prize for medicine and physiology to Karl von Frisch, Konrad Lorenz and Niko Tinbergen marks the full emergence of the study of animal behaviour from one of the less respectable corners of natural history to the forefront of the biological sciences. Before the $1930 \mathrm{~s}$ most studies of animal behaviour were conducted under conditions which bore little or no relation to those for which the animal was adapted, and yet were thought to provide material for almost limitless generalisations. Alternatively they involved field studies of individual species, sometimes conducted with great insight but with little apparent generality. Konrad Lorenz's great contribution was made possible by a quality which students of behaviour had come to look upon as a mere nineteenth century virtue-the ability to observe with insight. Through this he acquired an extraordinarily detailed knowledge of a few species and a broader knowledge of many others. This permitted him to attempt generalisations which began to weld the biological studies of behaviour into a coherent whole.

As a biologist his early interests were in the evolution of behaviour, and he focused on stereotype movement pat: terns as providing material for the comparative studies of closely related species. This simultaneously involved him in studies of internal causation on the one hand and ontogeny, including perceptual development and imprinting. on the other. Previous to Lorenz's work, the 'problem of instinct', though raised acutely by Darwin, had been largely ignored because the terms used in its discussion were ill-defined or meaningless and their relation to each other obscure. Lorenz, using concepts derived from a variety of sources in the United States and Europe as well as new ones of his own, produced for the first time a general system of behaviour with reference to both 'instinctive' and 'learned' aspects which showed at what point observational and physiological work could most effectively be directed. This released a torrent of research in the following thirty years. Inevitably there are some issues on which Lorenz turned out to be incorrect. His energy model of motivation, inherited from Freud and McDougall, which led him into insecure speculation about the nature of aggression is now generally seen to be misleading; his early attempts to divide behaviour into innate and acquired elements he later refined into a dichotomy of sources of information for adaptedness; and he has often been too ready to generalise from animal to man. On such issues as these popularisers have done further harm by misunderstanding and dramatising the issues. But it is indisputable that Lorenz imparted a momentum to the study of behaviour it has not since lost.

Lorenz is an acute observer. But he has never been an experimentalist. Both von Frisch and Tinbergen have used an experimental approach but neither has felt that the only way to do experiments on behaviour is to bring the animal into a carefully controlled laboratory setting-rather the experiment must often be taken to the animal in its natural environment. Von Frisch's major behavioural work arose from the manifest absurdity of $C$. von Hess's claim that bees were colourblind. The claim had been based on a grotesque experiment in which bees had been confined in darkened boxes with variously coloured exits. Because they chose at random they were assumed to be colourblind. Since bees appeared to use colour in feeding, von Frisch started a careful examination of their foraging behaviour. This led him to discover the now widely known communication system of the bee dances. By the very nature of the problem he was forced to experiment in the field. Only because he did so did he discover the dance.

Tinbergen's early work was guided by the great tradition of natural history in Holland, and primarily involved seal studies. In 1938 Lorenz invited him to his laboratory in Austria, and the year they spent together, rudely interrupted in 1939, was crucially important. Tinbergen moved to England a few years after the war.

Before he left Holland, Tinbergen had already initiated three major lines of work which have continued to occupy him and his students. One was concerned with ways in which predatory insects orient in their natural environment, and another involved studies of the life history of the herring gull. The third and perhaps the best known was made possible by the choice of a species al- most ideal for experimental studies-the three-spined stickleback. Its great merit arises from the fact that it is possible to create in a laboratory tank a near natural environment where experiments can be carried out with great precision. Its choice by Tinbergen was no mere matter of luck.

Perhaps the most important landmark in this field of science was Tinbergen's publication, in 1951, of The Study of Instinct. This brought together the products of his earlier field studies, of his studies of sticklebacks, and of his collaboration with Lorenz. Perhaps even more important was the way in which it delineated the problems comprised in behaviour study-not only the problems of its immediate causation, but its development in the individual, its evolution and its adaptedness. From this point on there was both a central body of theory and a basis of hard facts from which to proceed-and also some indication of how to proceed, with careful observation preceding experiment, and resynthesis accompanying analysis to avoid the reductionist fallacy. Although some parts of the book came in for criticism, it proved to be a major inspiration for behaviour studies through the fifties and sixties.

Three qualities of Tinbergen's work require special mention. First it is he who really perfected the field experiment. While observation always precedes experiment in his work, the one merges into the other in a manner that permits a biologically valid analysis. Second, by applying this method Tinbergen has opened up a previously almost totally neglected set of problemsthe adaptedness of behaviour. The issue is raised by comparative studies; just why is it that closely related species differ in their behaviour? By careful field experiments Tinbergen has demonstrated the adaptive significance of many aspects of gull behaviour and shown how the different behavioural characters of a species fit together to form an integrated and adapted whole. Finally, in a subject which too easily lends itself to woolly thinking, Tinbergen's clarity set standards which all can now attempt to emulate. The importance of this cannot be overemphasised in an area where limited lessons about our own behaviour are to be learned, but slick generalisations are easy.

This award has not been made for the solution of a particular problem in an established field, but for the creation of a new science-ethology, the biological study of behaviour. Konrad Lorenz, Karl von Frisch and Niko Tinbergen have nurtured it through the storms and controversies that accompanied its emergence, and richly deserve the recognition they now receive. 